\title{
El Partido Socialista y El Hogar Obrero. Un análisis de las primeras experiencias cooperativas en el cambio de siglo
}

\author{
María Natalia Rabasa \\ Universidad de Buenos Aires, Argentina - Consejo Nacional de Investigaciones Científicas y Técnicas - \\ Centro de Estudios Históricos de los Trabajadores y las Izquierdas \\ mnrabasa@gmail.com \\ ORCID: 0000-0002-1423-2000
}

Titulo: The Socialist Party and "El Hogar Obrero". An analysis of the first cooperative experiences at the turn of the century

Resumen: El artículo examina los antecedentes, la fundación y las primeras acciones de la cooperativa El Hogar Obrero (EHO), fundada en 1905 por impulso de Juan B. Justo y otros miembros del Partido Socialista (PS). Procuramos rastrear la lenta conformación del ideario cooperativo del PS desde sus orígenes; analizamos el escenario en el que se constituyó EHO y examinamos sus primeros proyectos llevados a cabo, así como sus alcances y limitaciones. Ello lo hacemos, principalmente, a través de La Vanguardia, órgano oficial del PS, así como con fuentes propias de la cooperativa como estatutos, actas de asamblea y de directorio y su publicación La Cooperación Libre.

Palabras claves: El Hogar Obrero - Partido Socialista - cooperativismo

\begin{abstract}
The article addresses the antecedents, the foundation and the first actions of the cooperative "El Hogar Obrero" (EHO), founded in 1905 at the impulse of Juan B. Justo and other members of the Socialist Party (PS). We attempt to trace the gradual formation of the cooperative ideology of the PS from its origins. We explore and analyse the scenario in which EHO was established,
\end{abstract}

DOI: https://doi.org/10.46688/ahmoi.n19.324

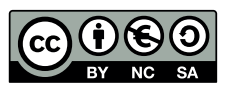

Obra bajo licencia Creative Commons 4.0 International (Atribución - NoComercial - Compartirlgual) 
its first projects carried out, as well as its scope and limitations. We achieve this, mainly, through La Vanguardia, the official organ of the PS, as well as with the cooperative's own sources such as statutes, minutes of assembly and board of directors, and its publication La Cooperación Libre.

Keywords: El Hogar Obrero - Socialist Party - cooperativism

Recepción: 25 de marzo de 2021. Aceptación: 3 de julio de 2021

$* * *$

En junio de 1896 se constituyó el Partido Socialista (PS) argentino, coronando así un proceso organizativo que se había iniciado casi una década atrás. Al poco tiempo, Juan B. Justo se hizo de la conducción del partido y comenzó un lento e incesante camino en el que buscó imprimirle su orientación programática. Consolidado como una alternativa moderada y progresista, el PS apuntó al "perfeccionamiento de las instituciones democráticas, el mejoramiento de las condiciones de vida de las clases subalternas y la modernización del país" (Camarero, 2015). A poco de su creación el partido estableció que la lucha socialista se debía dar en tres áreas: la política, la gremial y la cooperativa.

Por impulso de Justo y otros dirigentes del PS, el 30 de julio de 1905 se fundó una cooperativa de crédito y edificación a la que denominaron El Hogar Obrero (EHO). Por trayectoria y longevidad puede ser considerado el proyecto cooperativo de mayor envergadura llevado adelante por el Partido Socialista. A pesar de su importancia, ha sido escasamente abordado por la historiografia. Las primeras elaboraciones sobre su historia han sido escritas por personalidades de EHO y, aunque acríticas, ofrecen una reconstrucción pormenorizada del itinerario de la cooperativa (Repetto, 1976; Carracedo, 1980). El trabajo de Verónica Ronchi (2016) se constituye como la primera historia institucional de EHO realizada desde un ámbito académico, donde se prioriza la exposición de datos por sobre el análisis. Anahí Ballent (2014) realizó un estudio sobre los proyectos habitacionales entre su fundación y 1941, a través de un análisis global que entrecruza vivienda y ciudad. Por su parte, el PS ha sido abordado desde múltiples perspectivas, tales como su acción política (Wellhofer, 1975; Walter, 1977; Adelman, 1989; Martínez Mazzola, 2008; Poy, 2020); su vínculo con el movimiento obrero (Horowitz, 2004; Iñigo Carrera, 1996; Camarero, 2015; Tortti, 1989; Ceruso, 2017); la experiencia cultural y educativa (Barrancos, 1991; Becerra, 2003); sus intelectuales (Graciano, 2015); el rol de las mujeres dentro del partido (Barrancos, 2005; Palermo, 2018), entre tantos otros puntos de análisis, pero donde el cooperativismo, a pesar de ser central en el despliegue del PS, aún no ha sido abordado en profundidad sino tangencialmente. El 
trabajo de Carlos Herrera (2016), centrado en el período 1945-1955, es de los pocos que examina el PS desde sus tres esferas de acción.

El presente trabajo, que pretende encarar lo que consideramos una vacancia historiográfica, tiene por objeto analizar los inicios de El Hogar Obrero en el marco del proyecto socialista. Para ello es necesario reconstruir cómo se forjó al interior del PS el ideario cooperativo e indagar sobre los ensayos previos a EHO. Por lo tanto, nuestro recorte temporal abarca desde los años previos a la fundación del Partido Socialista hasta entrada la década de 1910.

¿Cómo se constituyó la doctrina cooperativa del PS? ¿En qué escenario se fundó $\mathrm{EHO}$ ? ¿Qué alcances y limitaciones tuvo la cooperativa en los primeros años de existencia? ¿Cuál fue el vínculo que se tejió entre el PS y EHO? Para nuestra investigación, guiada por estas preguntas, nos serviremos, principalmente, de fuentes como La Vanguardia, órgano del PS, documentos propios de EHO como estatutos, actas de asamblea y de directorio, y su publicación oficial, La Cooperación Libre, entre otras.

\section{Los inicios cooperativos del Partido Socialista}

Juan B. Justo se interesó tempranamente por el cooperativismo, doctrina que estaba en boga entre los socialistas europeos a fines del siglo XIX. Si bien habria que esperar al Congreso de Copenhague de 1910 para que la Segunda Internacional ${ }^{1}$ abordara profundamente este tópico, lo cierto es que ya era un tema contemplado en la Asociación Internacional de Trabajadores y discutido por las corrientes socialistas incluso con anterioridad. Como hombre vinculado al movimiento socialista internacional (Aricó, 1999), Justo se encontraba al corriente de algunas experiencias cooperativas, tanto locales ${ }^{2}$ como extranjeras, y también de sus principales exponentes europeos, tales como Robert Owen, Louis Blanc, Charles Fourier, entre tantos otros.

Su temprana atracción por el cooperativismo se plasmó en algunos escritos publicados en La Vanguardia antes de la fundación del PS. En su primer artículo sobre este tema, que data de 1894, se limitó a reproducir algunos datos sobre dos cooperativas en particular, una italiana y otra belga, las cuales, desde su perspectiva, probaban los beneficios de

1. Sobre el debate en torno a las cooperativas en el Congreso de Copenhague, ver Vandervelde (1913), Lenin (1977).

2. En el último cuarto del siglo XIX, se desarrollaron varias experiencias cooperativas en Argentina, fundadas en su mayoría por inmigrantes. De tinte socialista, podemos nombrar dos: la Cooperativa de Pan, iniciada por alemanes en 1888 y la Cooperativa de Consumo, creada por un grupo de emigrados franceses en 1885. Ambas tuvieron una corta vida (Repetto, 1944). 
este tipo de sociedades, ya que mejoraban las "condiciones materiales de vida del obrero" y permitian "emplear y desarrollar sus aptitudes para la asociación y la cooperación voluntaria e inteligente". ${ }^{3} \mathrm{Al}$ año siguiente realizó un viaje a Europa que le permitió tener una visión de primera mano de los avances y las características del movimiento cooperativo. En su recorrido procuró conocer las experiencias socialdemócratas siendo Bélgica el país que, desde la óptica de Justo, había alcanzado el mayor desarrollo en este aspecto. La Vooruit de Gante y la Maison du Peuple de Bruselas, ambas adheridas al Partido Obrero Belga (POB), eran la prueba de la potencia cooperativa: además de ser "grandes escuelas de asociación y administración", ${ }^{4}$ eran provechosas para el partido, puesto que traccionaban asociados a sus filas "que de otro modo no ingresarian a él" ${ }^{\prime}$ destinaban parte de las utilidades a propaganda partidaria. A la vez, los tres diarios del POB habían sido fundados y sostenidos por la cooperativa de Gante y por La Presse Socialiste, rama de la Maison du Peuple. ${ }^{6}$ El socialismo belga se presentaba como un modelo ejemplar donde el ala cooperativa, además de los múltiples beneficios para la clase trabajadora, servía directamente a los fines del partido.

Durante el congreso fundacional del Partido Socialista, Justo pronunció el discurso en nombre del Comité Ejecutivo. En un pasaje de su exposición resaltó la necesidad de observar el devenir de los partidos socialistas europeos a fin de aprovechar la experiencia acumulada. En ese sentido, comparó los casos de Inglaterra, Alemania y Bélgica:

En la primera empezó como movimiento gremial, y así conserva siendo esto una de las causas de su estancamiento y de atraso; en Alemania predominó el carácter político del movimiento, y en esa forma ha adquirido gran desarrollo; en Bélgica, donde empezó después, al carácter gremial y político, se agrega desde un principio el elemento cooperativo, y en esta forma llega a adquirir una importancia relativa mayor que en cualquier otra parte. ${ }^{7}$

El arquetipo belga presentaba un equilibrio entre el desarrollo político y gremial, a la vez que adicionaba el elemento cooperativo, superando

3. "Cooperativas obreras: dos buenos modelos", La Vanguardia, 3 de noviembre de 1894 , p. 1.

4. "Cooperativas socialistas", La Vanguardia, 26 de octubre de 1895, p. 1

5. "Cooperativas socialistas", La Vanguardia, 26 de octubre de 1895, p. 1

6. "Las cooperativas socialistas", La Vanguardia, 2 de noviembre de 1895, p. 2.

7. "E1 Primer Congreso Socialista Obrero Argentino. Primera sesión", La Vanguardia, 4 de agosto de 1896, p. 1. 
al caso inglés y al alemán. Lo cierto es que el POB era una federación de organizaciones socialistas, secciones sindicales y cooperativas de consumo (Kriegel, 1986); y si bien eso no era exactamente lo que quería replicar, Justo reparaba en que aquella experiencia le permitiria posicionar la organización partidaria con tres esferas de acción.

Las ideas sobre cooperativismo, que hasta el momento se encontraban dispersas en breves artículos, fueron sintetizadas y explicadas con mayor detenimiento por Juan B. Justo en una conferencia realizada en diciembre de 1897. Allí mostró una conformación más acabada de su doctrina que, aunque no estaba exenta de contradicciones, se constituyó como "la primera teorización justista" sobre el tema (Herrera, 2016, p. 100). En aquella disertación expuso los principios básicos del cooperativismo, recapituló los aportes de sus grandes teóricos y repasó las experiencias europeas. A la vez, diferenció las cooperativas de producción de las de consumo, inclinándose por estas últimas ya que eran más viables por no requerir ni grandes capitales ni extensos estatutos. En palabras de Justo, las cooperativas de consumo eran

una manifestación más elocuente aún del poder económico de la clase obrera. Ellas mejoran el modo de vivir de los asociados, aceleran la evolución industrial, suprimiendo los pequeños productores y comerciantes, educan a los cooperadores y son al mismo tiempo una prueba de su educación. ${ }^{8}$

Por otro lado, si bien insistió en que era necesario desplegar los tres campos de acción, afirmó que la cooperación no reemplazaba la acción gremial y política. De hecho, entre ellos se establecería una interrelación: por ejemplo, el ámbito cooperativo debía ser defendido con acción política. ${ }^{9}$ Distanciándose del modelo belga que había exaltado dos años atrás, Justo planteó que era un error enlazar la cooperación a los fines del partido, tal como hacía la Maison du Peuple, que explicitaba en la libreta de cada cooperador que la sociedad era "un grupo político socialista". En ese sentido, sentenció: "No nos dejemos cegar por preocupaciones de partido, ni engañar por los mirajes de la utopía. Hagamos cooperación por la cooperación misma, sin propósitos partidistas". ${ }^{10}$

En suma, en el breve período transcurrido entre 1895 y 1897 Justo forjó una primigenia conceptualización del cooperativismo que se amoldaba a la forma en la que él pretendía que tuviese el PS, un partido centrado en la acción política, que en su lógica equivalía a acción par-

8. “Cooperación obrera. Continuación”, La Vanguardia, 29 de enero de 1897, p. 2.

9. "Cooperación Obrera”, La Vanguardia, 15 de enero de 1898, p. 1.

10. “Cooperación obrera. Continuación”, La Vanguardia, 29 de enero de 1897, p. 2. 
lamentaria, y donde las otras acciones serian subsidiarias de aquella. Esas ideas estaban atravesadas por ciertas contradicciones, entre las que se destaca la más palpable: si el partido tenía que intervenir en tres áreas de acción, pero a la vez el cooperativismo no debía tener propósitos partidarios, ¿qué vínculo se establecería entre la acción cooperativa y la acción política? ¿Cuál sería, a su vez, la relación que se forjaria con el tercer plano, es decir, el gremial?

En aquel período inicial, el partido llevó adelante dos proyectos cooperativos: la Cooperativa de Publicaciones (CP) y la Cooperativa Obrera de Consumo (COC). La primera fue fundada en 1896, apenas unos dias antes del congreso constituyente del Partido Socialista. Inspirada en la práctica belga, la CP surgió del impulso de Juan B. Justo y Augusto Kühn, con el propósito de crear una sociedad que respondiera a los fines del partido e imprimiera, principalmente, La Vanguardia. El reglamento de La Presse Socialiste de Bruselas se tomó de ejemplo, y fueron Justo, Kühn y Juan Schaefer los encargados de redactar uno propio. Nacía así la Cooperativa de Publicaciones con un doble objetivo: adecuar los bienes con los que se producía La Vanguardia al proceso de institucionalización partidaria (Buonuome, 2014, p. 39) y fomentar la difusión de obras y periódicos socialistas. ${ }^{11}$

Por otro lado, y en consonancia con las ideas promulgadas en la conferencia de 1897, por iniciativa de Justo se fundó en 1898 la COC. El estatuto de esta nueva sociedad demostraba la completa adhesión a los principios rochdalianos: ${ }^{12}$ se determinaba la incorporación voluntaria de los asociados; el capital de la cooperativa se formaria con las acciones de sus socios; cada socio representaria un voto; habría neutralidad politica y religiosa; las compras se harian al contado, sin incorporar el crédito. Desde las páginas de La Vanguardia se celebró el surgimiento de la COC afirmando que constituía uno de los primeros pasos para materializar las ideas presentes entre ellos hacía años y se invitó a todo trabajador que tuviese la posibilidad económica a asociarse cuanto antes "en bien de sí mismo, de su familia y de la clase trabajadora en general". ${ }^{13} \mathrm{La}$ Cooperativa Obrera de Consumo inició sus ventas en diciembre de aquel año, y si bien la lista de productos ofrecidos era muy escueta, lentamente se fue ampliando. ${ }^{14}$ Únicamente los socios podían comprar

11. "Cooperativa de Publicaciones”, La Vanguardia, 20 de junio de 1986, p. 1.

12. En 1844 veintiocho tejedores de la localidad inglesa de Rochdale fundaron una cooperativa de consumo llamada Rochdale Equitable Pioneers Society. Alli se establecieron unos principios básicos que luego se convertirian en la base del movimiento cooperativo moderno.

13. “Cooperativa de Consumo”, La Vanguardia, 13 de octubre de 1898, p. 1.

14. Cuando abrió sus puertas, la COC vendía yerba, aceite italiano, kerosene, arroz, 
alli y las transacciones se realizaban unos pocos días a la semana en horario nocturno. La sociedad funcionó en la calle México 2070, sede del Centro Socialista Obrero, donde también se localizaban la Asociación Obrera de Socorros Mutuos, la Biblioteca Obrera, la redacción, imprenta y administración de La Vanguardia, y varias sociedades de ebanistas, tejedores, escultores, entre otros.

En paralelo al surgimiento y consolidación de la COC, la Cooperativa de Publicaciones evaluaba cómo continuar sus actividades. En 1899 reformó sus estatutos y abandonó su adhesión al PS. Este quiebre con el partido se debía a la necesidad de obtener el reconocimiento legal: "pues sin la personería jurídica esta no tendría facilidad ni seguridad de sus operaciones, y es sabido que, si aparece ligado al Partido Socialista o a las ideas, le será imposible hacerse autorizar por el Estado como sociedad anónima". ${ }^{15}$ De todas maneras, la ruptura del vínculo fue de tipo formal, ya que tanto las convocatorias a asambleas como sus publicidades continuaron apareciendo en La Vanguardia. Incluso, cuando se disolvió a finales de 1901, la CP decidió traspasar sus activos al PS, invitó a los asociados a ceder sus acciones al partido y el capital existente se donó en partes iguales al consultorio médico del Centro Socialista Obrero y a la biblioteca obrera. ${ }^{16}$ En los pocos años que funcionó, la cooperativa imprimió La Vanguardia, El Pintor, L'Emigrato y $A B C$ del Socialismo (Oddone, 1983, p. 277).

Por aquel entonces la Cooperativa de Consumo no corría mejor suerte. Poco tiempo atrás se habían propuesto diversas opciones para ampliar las ventas, tales como el pago de viáticos para aquellos socios que viviesen lejos o el reparto a domicilio. Nicolás Repetto, en nombre del Centro Socialista Norte, propuso reforzar el carácter socialista de la cooperativa y, en esa línea, se invitó a todos los centros socialistas a tomar acciones de la COC. A la vez, más cercano al modelo belga, se propuso destinar el 3\% de las ganancias brutas a la caja del PS, para propaganda. A pesar de los grandes esfuerzos, en 1902, con apenas trece socios presentes, se votó la disolución de la Cooperativa Obrera de Consumo. La comunicación en La Vanguardia la firmó Máximo Schulze, quien unas semanas atrás había informado el mismo destino que había tenido la Cooperativa de Publicaciones.

La puesta en práctica había ayudado a los socialistas a definir su cuerpo de ideas sobre cooperativismo y a ganar experiencia en ese te-

sal fina y gruesa. A la semana sumó aceite nacional, café molido, chocolate, jabón y garbanzos. Al año siguiente la lista ya incluía distintas marcas de galletitas, harina, dulce de membrillo, velas, fideos, porotos chilenos y distintos tipos de cafés.

15. “Cooperativa de Publicaciones”, La Vanguardia, 29 de julio de 1899, p. 3.

16. "La Cooperativa de Publicaciones", La Vanguardia, 11 de enero de 1902, p. 2. 
rreno, que volcarian años después en una cooperativa exitosa, con una vida casi centenaria, como fue El Hogar Obrero.

\section{La fundación de El Hogar Obrero y el debate cooperativo en el mundo gremial}

Tras la disolución de la CP y la COC, el tema cooperativo seguía en agenda. En el VI Congreso del Partido Socialista, realizado en 1904, se resolvió "declarar necesario fomentar la propaganda en pro de las cooperativas". ${ }^{17}$ En esa línea, el PS difundió algunos proyectos a través de La Vanguardia, como el ideado por la Asociación de Socorros Mutuos para producir pan, ${ }^{18}$ y también acompañó o brindó algún tipo de ayuda, como a la Cooperativa de Obreros Herradores, quienes utilizaron las instalaciones del local de México 2070 para vender sus acciones. ${ }^{19}$

Promediando el mes de julio de 1905, unos veinte afiliados del PS se reunieron con la iniciativa de adquirir un local para el partido, pero también para La Vanguardia, la Unión General de Trabajadores y la Cámara de Trabajo. Se acordó constituir una sociedad titulada "Casa del Pueblo" y se comenzaron a reunir fondos en vistas de iniciar las acciones necesarias para adquirir un establecimiento propio. Se convocó a una asamblea para el día 30 de julio, en horario nocturno, en la sede partidaria de la calle México. En ella se daría lectura a los estatutos revisados por Enrique Del Valle Iberlucea y se nombraría al primer directorio que se encargaría de expandir la "empresa proletaria". ${ }^{20}$

La agenda socialista habia fijado otra asamblea para aquella fecha, en horario de la tarde, a realizarse en el local del Círculo Artístico, situado en el centro porteño. Esta tenía como finalidad la fundación de una cooperativa de préstamos y construcción, proyecto que había sido presentado a principio de mes desde La Vanguardia como la idea de "un grupo de ciudadanos" preocupado por el problema de la vivienda y con la convicción de "hacer socialismo práctico". ${ }^{21}$ Juan B. Justo fue el gran impulsor de esa asamblea, y junto a Nicolás Repetto, Ángel Giménez, Enrique Dickmann y otros quince hombres vinculados al PS fundaron una cooperativa que bautizaron El Hogar Obrero. El objetivo de esta nueva sociedad era brindar, a través del esfuerzo mancomunado de sus

17. "Sexto Congreso del Partido Socialista. Tercera sesión", La Vanguardia, 2 de julio de 1904 , p. 2.

18. "Cooperativa en proyecto", La Vanguardia, 11 de junio de 1904, p. 2.

19. "Cooperativa de Obreros Herradores", La Vanguardia, 18 de junio de 1904.

20. "Pro-Casa del Pueblo", La Vanguardia, 29 de julio de 1905, p. 1.

21.“Cooperativa de construcción”, La Vanguardia, 1 de julio de 1905, p. 2. 
asociados, una respuesta a uno de los problemas más acuciantes para la clase trabajadora: la vivienda.

En la asamblea, presidida por Repetto, fue Justo el que tomó la palabra y explicó la utilidad de formar una cooperativa que proporcionase créditos y edificase hogares para aquellas personas que pudieran realizar pequeños ahorros. Serian tres las operaciones que realizarian: prestar dinero para edificación, con garantía hipotecaria; comprar terrenos y construir casas para luego venderlas o rentarlas; prestar dinero a los socios en casos especiales (Repetto, 1976, p. 18). El proyecto de estatuto, discutido y aprobado en aquella reunión, no hacía mención alguna al Partido Socialista: ni adhesión partidaria ni destino de utilidades.

Con EHO ya fundado se desarrolló la mencionada asamblea de la Casa del Pueblo. Adrián Patroni explicó las decisiones que se habían tomado en aquella reunión:

Creímos oportuno en la asamblea llevada a cabo el domingo a la noche para los trabajos pro-Casa del Pueblo dar por disuelta la sociedad en cuestión aconsejando a sus adherentes y a la clase obrera en general se inscriban como socios de El Hogar Obrero, toda vez que esta asociación -si así lo manifestara gran número de sus accionistas-se interesará en la construcción de un gran local para las organizaciones obreras, ya que hallaría en ello un medio de tener una buena renta, prestando a la vez un señalado servicio a la clase trabajadora. Los presentes en aquella asamblea así lo resolvieron incorporándose en el nuevo organismo cooperativo. ${ }^{22}$

El proyecto de la Casa del Pueblo, tal vez ideado originalmente con una impronta más vinculada al partido, quedaba trunco o en el mejor escenario postergado. La nueva cooperativa formada por cuadros del PS, pero sin adherencia explícita al partido, lo había absorbido.

Cuando El Hogar Obrero se dispuso a comenzar con sus primeras acciones tuvo que hacer frente a un gran obstáculo. Aquel año se había aprobado en la Cámara de Diputados un proyecto de ley que establecía que toda sociedad por acciones, incluidas las cooperativas, debían pagar una patente anual cuyo monto oscilaba entre los $\$ 1.000$ y los $\$ 7.000$. En ese escenario, los socios Repetto y Patroni se entrevistaron con el presidente de la Comisión de Hacienda del Senado para solicitarle la modificación de la patente. Sin un resultado favorable, en septiembre de 1905 se envió una carta a la comisión de presupuesto del Senado en la que se explicitaba que El Hogar Obrero era "una verdadera institución

22. "Pro-Casa del Pueblo. Cooperativa de préstamos y construcción «El Hogar Obrero"", La Vanguardia, 5 de agosto de 1905, p. 1. 
popular creada por y para gente laboriosa y modesta”, ${ }^{23}$ en la que cada uno aportaba en beneficio del bien común, siendo las patentes una prohibición a su desarrollo, como también ocurriría con otras cooperativas obreras. Las argumentaciones fueron desoídas.

Como ya lo había anticipado Justo años atrás, la cooperación debía ser defendida en el terreno político. En julio de 1906 Alfredo Palacios presentó un proyecto de ley para eximir a las cooperativas del pago de patentes. En su discurso en la Cámara de Diputados repasó los grandes beneficios del cooperativismo, con gran presencia en países como Bélgica, Inglaterra, Francia, Suiza y Alemania. El objetivo de su exposición era emparentar el funcionamiento de las cooperativas obreras con los valores del progreso y el desarrollo imperante en "las naciones más adelantadas del mundo", mientras que en Argentina:

Solo tenemos empresas equívocas, demasiado turbias, casas trampas, donde los incautos depositan los ahorros que han de enriquecer a los iniciadores del negocio. [...] en Inglaterra, en Bélgica, en Estados Unidos, etc., las cooperativas que no ofrecen ganancias a los especuladores, que no aseguran situaciones privilegiadas a los iniciadores, están exentas de impuesto de patente. Las leyes de esos países favorecen la implantación de las cooperativas obreras [...] Modificar nuestra ley de patentes, en este punto, es progresar, incorporándonos al movimiento civilizador de otros países que favorecen la asociación de obreros en instituciones realmente populares. ${ }^{24}$

En definitiva, para el Partido Socialista el cooperativismo aparejaba, por lo menos, dos grandes beneficios: por un lado, una mejora material para la clase trabajadora; por otro, funcionaría como una herramienta civilizadora, que ayudaría al progreso y a la modernización del país.

Finalmente, el proyecto fue aprobado en enero de 1907 y a partir de entonces se exceptuaron del pago de patentes a las sociedades cooperativas que no tuviesen capital preferido y que no asegurasen en su administración a los iniciadores. ${ }^{25}$ Con ese obstáculo superado, el paso siguiente fue conseguir la personería jurídica de la sociedad, que se obtuvo gracias a los trámites llevados a cabo por Mario Bravo. En junio

23. "Pro-Hogar Obrero", La Vanguardia, 22 de septiembre de 1905, p. 1.

24. "Por las cooperativas obreras. Discurso del diputado Palacios", La Vanguardia, 26 de julio de 1906, p. 1.

25. Diario de Sesiones de la Cámara de Diputados 1906. Tomo II: Sesiones Extraordinarias, Talleres Gráficos de la Penitenciaría, 1907, p. 1185. 
de aquel año, a casi dos de haber sido fundado, EHO se encontraba en condiciones de iniciar sus actividades.

El PS avanzaba en su despliegue cooperativo en un escenario en el que la temática distaba de ser ajena al movimiento obrero. Por caso, la Federación Obrera Argentina (FOA), que había surgido en mayo de 1901 con presencia anarquista y socialista, abordó esta temática en su II Congreso desarrollado en abril de 1902. Fue allí donde se produjo el quiebre entre ambas corrientes, siendo los socialistas quienes abandonaron el congreso. Con los votos anarquistas, se acordó recomendar la creación de cooperativas de consumo ya que suprimían los intermediarios que "explotan y envenenan", mientras que las cooperativas de producción "solo deben aceptarse como medio accidental de defensa". ${ }^{26}$ Por pedido de varios integrantes de la federación, en La Organización Obrera, órgano de la FOA, se habilitó una sección para discutir sobre el tema cooperativas. ${ }^{27}$

Tras la fundación de la Unión General de Trabajadores (UGT), central opositora a la FOA, orientada por dirigentes de filiación socialista, pero con fuerte presencia de los que luego engrosarian las filas del sindicalismo revolucionario, ${ }^{28}$ esta se posicionó a favor de las cooperativas a partir de su III Congreso, desarrollado en agosto de 1905, unos pocos días después de la fundación de EHO. Allí se consideró que "las instituciones de cooperación socialista son las más excelentes escuelas administrativas en que pueda adquirir la clase trabajadora la necesaria competencia para gestionar un día sus propios intereses con completo conocimiento de causa" y, a la vez, proporcionaban a los trabajadores "beneficios de orden material, y positivos tales como condiciones mejores de trabajo y seguridad, dificiles de obtener en los talleres de propiedad privada". Por lo tanto, resolvió:

Incitar a los trabajadores organizados a la implantación de cooperativas de molde socialista en aquellos gremios industriales en que el proyecto sea de factible realización, con el objeto de mejorar las condiciones de trabajo e intensificar nuestra propaganda, procurando excluir de ellas todo sentimiento de estrecho corporativismo; y reclamar de las asociaciones adheridas a la Unión el estudio de un plan a realizarse de cooperativa socialistas de consumo y de producción de artículos de primera necesidad para utilidad entera de la clase trabajadora argentina

26. " $2{ }^{\circ}$ Congreso gremial de la Federación Obrera Argentina", La Organización Obrera, abril de 1902, p. 2

27. "Sobre cooperativas", La Organización Obrera, septiembre de 1902, p. 2.

28. Sobre la fundación de la UGT y los vínculos con el PS, ver Belkin (2020). 
y que puedan en momentos críticos de la lucha contribuir a robustecer su resistencia al capitalismo. ${ }^{29}$

Por su parte, la FOA tomó una postura crítica al cooperativismo en su III Congreso, de 1903, calificando tanto a las cooperativas de consumo como a las de producción como "perjudiciales a la clase trabajadora" porque fomentaban la ambición (Bilsky, 1985, p. 202). De todas formas, el rechazo se tornó más categórico en 1906, durante el VI Congreso de la Federación Obrera Regional Argentina (FORA), llamada así desde 1904 y estatutariamente afin al comunismo anárquico desde 1905:

Considerando que las cooperativas, por ser obras de acumulación, son contrarias a la acción de los obreros; que el mayor éxito de estas equivale a un alto mejoramiento económico de los cooperativistas, son contrarias al principio de la emancipación de los trabajadores, puesto que la acción de estos dentro de las cooperativas es velar por la conservación de sus capitales y puesto que esa defensa de interés es un egoísmo puramente burgués y no la emancipación del capital [...]. El $6^{\circ}$ Congreso declara: Puesto que el éxito de los cooperativistas es la derrota de los proletarios; puesto que, cuando triunfan, son instituciones burguesas que aceptan la ley y a ella recurren para perseguir a sus deudores, descuentan giros de dinero, colocan sus capitales y especulan en sus empresas terminando con ser un verdadero enemigo del proletariado, recomiéndase a todas las sociedades que combatan por todos los medios la implantación de cooperativas (Bilsky, 1985, p. 221).

En un contexto donde el cooperativismo era un eje de debate en el movimiento obrero, pero también en el PS, El Hogar Obrero se encontraba en condiciones de comenzar a operar. Se daba inicio así a una cooperativa que empezaria a crecer en proyectos y asociados, hasta posicionarse, varias décadas después, como una de las empresas argentinas más importantes en término de volumen de negocios (Ronchi, 2016).

\section{El cooperativismo como solución. Las primeras acciones de El Hogar Obrero}

A principios del siglo XX, el paisaje porteño combinaba desde fabulosas mansiones de estilo francés hasta suntuosas obras arquitectónicas

29. “Cooperativas", La Unión Obrera, septiembre de 1905, p. 5. 
con cientos de conventillos donde vivian miles de familias obreras. ${ }^{30}$ Como es conocido, desde el último tercio del siglo XIX este tipo de vivienda precaria devino en una de las formas de habitación más extendidas en la ciudad, en un marco de enorme crecimiento demográfico. El hacinamiento, la falta de aire y luz y los materiales utilizados transformaban a estos lugares en focos de enfermedades infectocontagiosas (Armus, 2007), algo que los socialistas, desde una mirada higienista, observaron con preocupación. ${ }^{31}$ Como señala James Scobie (1977), otra parte de la población porteña habitaba en pensiones, departamentos pequeños o casas que albergaban a más de una familia, donde las condiciones de vida generales no distaban demasiado de las del conventillo. Ante esta problemática, existieron algunos proyectos estatales para construir viviendas destinadas a trabajadores, aunque no llegaron a representar una respuesta significativa, incluso otros tantos nunca se realizaron. Los socialistas estaban informados al respecto, y desde La Vanguardia lanzaban críticas y sospechas. ${ }^{32}$ Este era el escenario en el que El Hogar Obrero alegaba intervenir.

Una vez habilitada para operar, la cooperativa empezó a buscar terrenos en remates públicos en vistas de construir viviendas rápidamente. A mediados de 1907, una comisión designada por el directorio compró cuatro lotes en el actual barrio porteño de Villa Luro, donde se proyectó levantar cuatro casas, una con tres dormitorios y las restantes con dos. Por reglamento, las casas se venderian al mejor postor, tomando como base su costo ${ }^{33}$ y en este caso los valores de referencia fueron entre $\$ 5.000$ y $\$ 6.900 .{ }^{34}$ Para acceder a una, el socio debía tener el $10 \%$ del valor de la propiedad en el capital social y pagar una mensualidad cercana a los $\$ 60$.

Mientras EHO se encontraba construyendo ese pequeño grupo de viviendas, se estaba desarrollando en la ciudad de Buenos Aires la llamada huelga de inquilinos. Si bien el PS reconoció como válido el reclamo, se distanció de la estrategia. Esta concepción no era nueva, pues ya en 1897 ante una posible huelga de este estilo, desde La Vanguardia se

30. Para un análisis de la ciudad de Buenos Aires hacia el cambio de siglo ver Liernur, 2014.

31. Uno de los socialistas higienistas más destacados que formó parte del núcleo fundacional de EHO fue Ángel Giménez. Obtuvo su título de médico luego de defender su tesis en 1901, titulada "Consideraciones sobre higiene del obrero en Buenos Aires".

32. "Casas para obreros. Que no las hagan la municipalidad ni el gobierno" La Vanguardia, 31 de enero de 1909, p. 1; "La habitación económica e higiénica. Será del pueblo o no será" La Vanguardia, 3 de febrero de 1909, p. 1.

33. Art. 32, Reglamento de E1 Hogar Obrero, 1907.

34. "El Hogar Obrero", La Vanguardia, 24 de noviembre de 1907, p. 2. 
afirmaba que era "un grave error confundir la relación inquilino-propietario con la de obrero-patrón". ${ }^{35}$ Diez años después mantenían una postura similar, advirtiendo que el origen de los precios exorbitantes por habitaciones antihigiénicas era la falta de oferta de casas accesibles para obreros. Bajo su seudónimo Rienzi, Enrique Dickmann señalaba:

Faltan casas. Tal es el mal. Hay que construir muchas viviendas cómodas y baratas. Tal es el remedio. Hay que estimular y fomentar por todos los medios la edificación de casas para obreros, o para hombres, como alguien dijo. Y no cabe duda de que no pagando el alquiler y dañando a la propiedad, rompiendo puertas y ventanas, no se fomenta la edificación de nuevas casas. Todo lo contrario. [...] Las cooperativas de edificación son eficacísimas para realizar una parte del ideal. Construir casitas para que sean habitadas por los mismos socios y con el alquiler ir amortizando el valor de la propiedad es contribuir eficazmente a la solución del problema. En ese sentido "El Hogar Obrero" es un modelo y es un ejemplo. Ojalá se multiplicaran y difundieran esta clase de instituciones. ${ }^{36}$

Así, EHO se presentaba como una solución frente a los problemas tanto estructurales como coyunturales de la clase trabajadora.

Los anarquistas, principales protagonistas de la huelga de inquilinos, rechazaron la postura socialista y criticaron fervientemente el cooperativismo. Desde La Protesta, calificaron a dicha doctrina como "una simpleza y una tontería" ya que pensar en "expropiar a la burguesía con el dinero de los obreros o constituir una producción netamente obrera frente a la producción que explotan los capitalistas, es un sueño muy lindo, pero de realización imposible". Los ácratas afirmaban que la posesión de una vivienda propia repercutía negativamente en el salario, pues aquel que no pagaba alquiler podría aceptar una merma en el jornal. A la vez, cuestionaban el alcance del cooperativismo, señalando que, si bien unos pocos obreros podían conseguir una vivienda por esa vía, eran "solamente algunos" ${ }^{37}$ En este sentido, es válido preguntar cuántos asociados accedieron a una vivienda a través de EHO en sus primeros años de actividad. Se debe contemplar que, hasta finales del año 1910, la cooperativa llevó adelante tres acciones: construyó casas individuales; prestó dinero para edificación con garantía hipotecaria, y levantó pequeños barrios obreros, donde cada unidad se vendía o alquilaba

35. "La cuestión alquileres", La Vanguardia, 18 de septiembre de 1897.

36. "El problema de la habitación”, La Vanguardia, 24 de noviembre de 1907, p. 1.

37. "La conquista del techo", La Protesta, 9 de febrero de 1909, p. 1. 
con opción a compra. Hacia finales de la década, cuando contaba con poco más de mil doscientos socios, ciento treinta asociados obtuvieron una vivienda gracias a EHO. Se desprende otro interrogante: ¿quiénes podían realmente acceder a una casa a través de EHO? Centrándonos en las construidas directamente por la cooperativa, podemos pensar que sus valores representaban un monto bastante elevando respecto al salario promedio de un obrero. ${ }^{38} \mathrm{El}$ directorio de $\mathrm{EHO}$ era consciente de eso, tal como lo manifestó en la asamblea ordinaria de febrero de 1909:

Hasta ahora las construcciones de El Hogar Obrero, a pesar de su modestia, no han estado al alcance de las familias trabajadoras, cuya cuota mensual entre alquiler y ahorro no puede pasar de veinticinco o treinta y cinco pesos. En Ramos Mejía ${ }^{39}$ hemos construido casitas de un tipo nuevo y económico [...]. La cuota mensual mínima para adquirir una de ellas, calculada sobre el costo, ha sido sin embargo de cincuenta y cinco pesos y sesenta centavos [...]. Necesitamos construir habitaciones más baratas [...] Debemos poner nuestro mayor empeño en construir casitas de tres mil pesos. ${ }^{40}$

El primer barrio obrero fue proyectado a comienzos de 1910, cuando el directorio compró un terreno en la localidad bonaerense de Ramos Mejía, a tres cuadras de la estación del ferrocarril. Allí se edificaron veintiuna casas, todas de igual tamaño y distribución, que seguian el modelo inglés cottage: comedor, pequeña cocina, baño en la planta baja y dos dormitorios en la planta superior. La inauguración de este conjunto de viviendas, un año después, fue una verdadera celebración a la que asistieron más de cuatrocientos socios. Justo pronunció un discurso en el que expresó que esas casas "eran la primera manifestación importante del pueblo trabajador del país para organizarse con fines económicos, la prueba visible de su aptitud para asociar sus ahorros y administrarlos por sí mismos, sin intervención de una clase directora

38. A modo de referencia, para el año 1909 en la ciudad de Buenos Aires, el salario diario de un maestro albañil era de $\$ 5$ a $\$ 5,50$; el de un oficial marmolero era de $\$ 5,50$ a $\$ 7$; un oficial talabartero cobrara alrededor de $\$ 4$; un prensista, de $\$ 4,50$ a $\$ 6$; el jornal de un oficial carpintero, oficial tornero u oficial alpargatero era de $\$ 4$ a $\$ 5$; oficiala en sombreros, de $\$ 3,50$ a $\$ 4$. Boletín del Departamento Nacional del Trabajo, $\mathrm{N}^{\circ} 10$, septiembre de 1909, pp. 352-359.

39. La cita refiere al segundo grupo de casas construido por EHO. En 1908 el directorio compró un terreno en Ramos Mejía, donde edificó cinco casas.

40. Acta de Asamblea de El Hogar Obrero N8, febrero 1909. 
y parasitaria" ${ }^{41}$ En este caso, los valores de cada casa rondaron los $\$ 4.000$, y sus mensualidades eran cercanas a los $\$ 45 .{ }^{42}$

Por aquel entonces, la cooperativa se encontraba ampliando sus áreas de acción. En 1909, por impulso de algunos asociados, se había comenzado a debatir la posibilidad de crear una sección de consumo, por lo que se formó una comisión especial para evaluar su factibilidad. Finalmente, luego de un gran consenso, se aprobó la creación de la nueva sección destinada a la compra, elaboración y venta de toda clase de artículos..$^{43}$ El Hogar Obrero, a poco de haber iniciado sus actividades, y presta a poner en práctica las enseñanzas que tiempo atrás había dejado la COC, se convertía en cooperativa de crédito, edificación y consumo.

Para garantizar su viabilidad, la flamante sección de consumos debía instalarse próxima a "sectores urbanos que concentraran población popular" (Ballent, 2014, p. 257). La cooperativa logró conjugar ese requerimiento con la necesidad de dar una respuesta a una problemática que atravesaban muchos socios: la imposibilidad de adquirir una vivienda propia. Desde La Cooperación Libre tiempo después explicarian:

La tarea de construir pequeñas casitas diseminadas por el extenso radio del municipio y sus arrabales no contribuía sino a medias a la solución del problema de la vivienda obrera que asume en esta capital aspectos realmente pavorosos. Era necesario pensar también, y, sobre todo, en aquellos obreros que por la índole de sus salarios están irremisiblemente condenados a vivir en una casa alquilada sin la esperanza de llegar a ser un día propietarios de la vivienda que ocupan. En una palabra, era necesario resolver el problema de la vivienda obrera colectiva suprimiendo los horribles aspectos y caracteres del clásico conventillo. ${ }^{44}$

El Hogar Obrero reconocía sus limitaciones y entendía que era necesario construir viviendas confortables, higiénicas y asequibles para la clase trabajadora. Se proyectó, entonces, la construcción de una casa colectiva en la ciudad de Buenos Aires, que fuese propiedad de la cooperativa, que ofreciese las viviendas en alquiler y que a la vez incorporase almacenes cooperativos.

41. "La fiesta de Ramos Mejía - Inauguración de 21 casitas para obreros", La Vanguardia, 10 de enero de 1911, p. 2.

42. La Vanguardia, 16 de agosto de 1910, p. 4.

43. Estatutos de El Hogar Obrero cooperativa de crédito, edificación y consumo (limitada), 1913.

44. "Breve reseña histórica", La Cooperación Libre, n 1, noviembre de 1913, p. 3. 
Hacia finales de 1910, el directorio adquirió un amplio terreno en Bolivar y Martín García, en la intersección de los barrios porteños de La Boca y Barracas. Allí construyó un edificio compuesto por sótano, planta baja, entrepiso y cuatro niveles con treinta y dos departamentos. Este proyecto, que plasmaba el tipo arquitectónico de casa colectiva, ofrecía diversos espacios comunes que habilitaban un habitar compartido. En el entrepiso se ubicó la Sociedad Luz, lo que significó el acceso a cursos y espacios de formación a quienes allí vivían. El Hogar Obrero puso a disposición una enorme biblioteca, con una gran cantidad de libros sobre diversos temas, entre ellos, cooperativismo. En la planta baja se localizó la sección de consumo, donde los socios de la cooperativa podian abastecerse de una amplia gama de productos.

El 9 de julio de 1913, en el aniversario de la Independencia argentina, fue inaugurada la primera casa colectiva de El Hogar Obrero. Juan B. Justo fue uno de los oradores, y en su discurso afirmó: "Nos asociamos a la solemnidad nacional del dia con este acto, que es también una fiesta de la independencia, de la independencia económica de los trabajadores" (citado en Repetto, 1976, p. 39). Al evento concurrieron decenas de socios y los miembros del directorio, a los que se les sumaron varios legisladores nacionales, algunos concejales porteños, delegados municipales uruguayos y el intendente municipal Joaquín Anchorena. En aquella ocasión, el PS demostraba lo que era capaz de realizar la acción cooperativa en beneficio de la clase trabajadora, pero también del país, puesto que ofrecía soluciones a problemas que el Estado desatendia.

Un año después, fueron inauguradas otras seis casas "higiénicas y baratas" 45 en la localidad de Turdera, evidenciando que el modelo de viviendas individuales no había sido abandonado. El terreno había sido comprado en remate en 1911, y allí se edificaron viviendas que contaban con dos dormitorios, baño, comedor, cocina pequeña y porche. Lentamente, se comenzó a instalar en la cooperativa un debate que, si bien en su superficie era arquitectónico, encubria aristas más complejas: "casa colectiva versus casa individual". Esta controversia, que seguiría latente por mucho tiempo, despertó diversos argumentos en torno a la vivienda, la sociabilidad y la propiedad. Este debate no sería exclusivo de los socialistas, pues hacia 1915, con la creación de la Comisión de Casas Baratas, llegaría también al Parlamento y a otros ámbitos estatales.

Otro rasgo por resaltar de este período fue el despliegue de la sección de consumo. Teniendo en cuenta que la vieja Cooperativa Obrera de Consumo había fracasado por las pocas ventas que realizaba, desde

45. "Página informativa. Sección construcción", La Cooperación Libre, $\mathrm{n}^{\circ}$ 1, noviembre de 1913, p. 4. 
El Hogar Obrero se trabajó fuertemente en atraer más asociados y que estos se abasteciesen en los almacenes cooperativos. En ese sentido, las mujeres comenzaron a ser interpeladas por ser vistas como las encargadas del hogar. Con los años este discurso se fue intensificando. En palabras de José Bogliolo, quien fuera presidente de EHO en la década del 30, las mujeres tenían una función vital para las cooperativas:

Dada la característica de los problemas que encara la cooperación, corresponde y debe preocupar esta acción en mayor grado a la mujer. Es ella la que tiene a su cargo la misión de adquirir los artículos de consumo, de abrigo, etc., y por lo tanto es quien maneja los dineros indispensables para su compra. Por eso mismo conviene hacerle conocer las funciones que realizan estas organizaciones ("las cooperativas son aliadas de las amas de casa, por cuidar su salud -ofrecer buenos productos-y sus dineros -no especular-"). La cooperación libre debe ser entendida por las madres. ${ }^{46}$

El área de consumo puso en el centro de la escena a las mujeres, pero en su rol de "mujeres domésticas": amas de casa, esposas y madres (Nari, 2004). Si bien excede al presente trabajo, podemos sugerir que, en las décadas siguientes, a medida que la sección se fue ampliando, les fue necesario fortalecer esta postura e instalar la idea de que era imprescindible que las mujeres comprendiesen la doctrina cooperativa y fuesen parte activa de EHO. ${ }^{47}$ Cabe preguntarse si este fue un discurso que quisieron imponer los varones de la cooperativa y del partido, o si fue compartido por las mujeres de dichos espacios. Una respuesta tentativa puede ser buscada en las palabras de socialistas cooperativistas, como ha sido Alicia Moreau de Justo, una de las pocas mujeres que integró el directorio de El Hogar Obrero. Ella afirmaba que:

un sistema económico basado sobre el interés del consumidor, como lo es la cooperación, debe apoyarse forzosamente, para su progreso y extensión, en la mujer y esta, a su vez, encontrar

46. "Exhortación a las mujeres en el día de la cooperación", Vida Femenina, julio de 1936, p. 12.

47. Esto puede verse en diversos artículos de La Cooperación Libre pero también en Vida Femenina, publicación del PS destinada a mujeres. Algunos ejemplos son: "Fidelidad cooperativista", La Cooperación Libre, no 2, diciembre de 1913, pp. 1-3; "Apoyo femenino en las cooperativas", Vida Femenina, junio de 1937, n 47, año IV, p. 7; "La mujer en el movimiento cooperativo", Vida Femenina, junio de 1937, n 47, año IV, p. 35. 
en el sistema cooperativo el medio más eficaz para llenar con toda eficiencia su función de directora económica de la familia. ${ }^{48}$

Las concepciones de Moreau de Justo pueden pensarse desde un "feminismo maternal", donde "la transformación de las mujeres en seres autónomos y actuantes, con dignidad social, no debería descuidar y menos romper la célula familiar, indispensable para anidar una buena sociedad" (Barrancos, 2005, p. 166).

\section{Conclusiones}

A poco de su fundación, el Partido Socialista estableció que sus terrenos de acción serían el político, el gremial y el cooperativo. Tempranamente, Juan B. Justo buscó establecer los lineamientos teóricos cooperativos, moldear su paso a la faz práctica e insertarlo en una lógica de lucha económica. Si en un primer momento fue el modelo belga el que más exaltó, puesto el estrecho vínculo entre el partido y las cooperativas, conforme pasaba el tiempo, el líder socialista comenzó a poner en entredicho los beneficios de esa simbiótica relación.

Como reflejo de ese ideario en plena conformación, hacia fines del siglo XIX se materializaron dos proyectos: la Cooperativa de Publicaciones y la Cooperativa Obrera de Consumo. La primera, adherida al partido y con su estatuto inspirado en el de La Presse Socialiste, fue un reflejo del prototipo que ofrecía Bélgica. Su creación fue simultánea a la constitución oficial del partido, por lo tanto, su origen se enlazó con la necesidad de institucionalizar los bienes y la impresión de su órgano oficial, como así también de folletos y otras publicaciones socialistas. La segunda, creada con posterioridad a la conferencia de 1897, puede pensarse como la concreción de varias ideas alli presentadas: la relevancia de las cooperativas de consumo por sobre las de producción, la factibilidad de llevarlas a cabo con poco capital y simples estatutos y el lábil, cuando no prescindible, nexo explícito con el partido. De todas maneras, y evidenciando las contradicciones todavía presentes, cuando la COC atravesó uno de sus peores momentos, las soluciones presentadas fueron pensadas en clave del modelo belga: reforzar su carácter socialista y destinar utilidades a las cajas partidarias para favorecer la publicidad.

Con una experiencia acumulada, y una doctrina aún en configuración, un grupo de socialistas, con Justo como principal promotor, fundó en 1905 la cooperativa de crédito y edificación El Hogar Obrero. Aunque su inicio no fue inmediato, raudamente se evidenció el modo en el que 
el partido buscó la vinculación de la esfera cooperativa con la política mediante el canal parlamentario. Cabe recordar que EHO no estaba ni adherido al PS ni destinaba utilidades al partido, entonces llegamos a una pregunta clave: ¿qué nexo se debía forjar entre el PS y EHO? ¿Y entre la acción política y la acción cooperativa? En los momentos fundacionales de El Hogar Obrero estos interrogantes parecian persistir dentro del PS, pero podría pensarse que para aquel entonces Juan B. Justo comenzaba a saldar esa disyuntiva a favor de una independencia de la acción cooperativa respecto del partido.

Para el socialismo, la acción cooperativa ofrecía grandes ventajas para la clase trabajadora brindando un sendero civilizatorio y educativo que permitía vehiculizarla como una herramienta de progreso y modernización para el país. En cuanto a las acciones concretas de El Hogar Obrero, observamos que en el período aquí analizado un puñado de asociados accedió a una vivienda a través de la cooperativa, ya sea adquiriendo las construidas por la sociedad o a través de préstamos hipotecarios. El modelo arquitectónico ensayado en un primer momento fue el de la casa individual, para luego dar lugar al de casa colectiva. Se originó al interior del PS y EHO un debate sobre cuál era el mejor modelo para llevar adelante, despertando diversos argumentos sobre vivienda, sociabilidad y propiedad. Queda como tarea a futuro analizar en detalle esta controversia y examinar cómo se materializó en los proyectos habitacionales.

Un acontecimiento importante en el desarrollo de EHO en sus primeros años fue la ampliación al área de consumo. Esta nueva sección puso en el centro de la escena a las mujeres por ser consideradas las directoras del hogar. ¿Este discurso se intensificó con el correr del tiempo? ¿Aumentó la presencia femenina en EHO en las décadas siguientes? Si fue así, ¿qué lugar ocuparon? Por otro lado, trazando un puente entre vivienda y género cabe preguntarse si las construcciones de EHO, tanto casas colectivas como individuales, plasmaron materialmente esta concepción de "mujeres domésticas".

Un tema que requiere profundización, especialmente para el período que se abre luego de la ley Sáenz Peña, es el modo en el que el PS y EHO se posicionaron frente al Estado. Mientras que a comienzos de siglo los socialistas se mostraban escépticos y críticos de la labor estatal, se observa que ese discurso se fue matizando con el tiempo. Ciertamente podría pensarse la acción cooperativa como un vector que le permitió al PS sumar una pieza más en su proyecto de institucionalización en la vida pública nacional. En ese sentido, se presentan los siguientes interrogantes: ¿influyó en EHO la mayor presencia de socialistas en el Parlamento? ¿Qué postura se adoptó respecto al rol del Estado en el terreno de la vivienda? 
Durante la primera década del siglo XX tuvo lugar la transformación de un concepto clave: si a fines del siglo anterior el partido hablaba de "cooperación socialista" o "cooperación obrera", a poco de fundado EHO se empezó a acuñar el término "cooperación libre”. Justo la definía de la siguiente manera:

La cooperación libre es la solidaridad para hacer y exige de los asociados un grado mucho más alto de capacidad histórica que la acción gremial negativa en las huelgas; es el campo en que los proletarios adquieren derechos y contraen obligaciones entre sí, entre iguales; es para ellos, permanentemente sujetos a la relación extorsiva del salario, la primera ocasión de un verdadero contrato. Y si bien participan en la cooperación libre elementos de distinta posición social, ella es ante todo uno de los métodos de la emancipación obrera, una de las modalidades de la moderna lucha de clases. (Justo, 1948: 405)

La cita ofrece una serie de concepciones que irian coagulando con nitidez en Justo y en el PS acerca de la intención de encauzar aquello que se entendia por emancipación obrera y lucha de clases en una práctica reformista, en plena utilización de los mecanismos de la democracia imperante y con objetivos civilizatorios. De modo evidente, el cooperativismo constituía allí una columna central a partir de la cual erigir el proyecto socialista.

\section{Referencias}

Adelman, J. (1989). Una cosecha esquiva. Los socialistas y el campo antes de la Primera Guerra Mundial. Anuario del IEHS, 4.

Aricó, J. (1999). La hipótesis de Justo. Escritos sobre el socialismo en América Latina. Sudamericana.

Armus, D. (2007). La ciudad impura: salud, tuberculosis y cultura en Buenos Aires, 1870-1950. Edhasa.

Ballent, A. (2014). Socialismo, vivienda y ciudad. La cooperativa El Hogar Obrero. En: A. Ballent y F. Liernur. La casa y la multitud. Vivienda, politica y cultura en la Argentina moderna (pp. 237-284). Fondo de Cultura Económica.

Barrancos, D. (1991). Educación, cultura y trabajo (1890-1930). CEAL

- (2005). Socialismo y sufragio femenino: Notas para su historia (18901947). En H. Camarero y C. Herrera. El Partido Socialista en Argentina: Sociedad, politica e ideas a través de un siglo (pp. 159-183). Prometeo.

Becerra, M. (2003), Socialismo, Estado y nación: un análisis de la producción de hegemonia educativa estatal en Argentina. Tesis de Maestría, FLACSO.

Belkin, A. (2020). La fundación de la Unión General de Trabajadores y 
sus vínculos con el Partido Socialista: Tendencias antipolíticas en el movimiento obrero argentino a comienzos del siglo XX. Izquierdas, 49, 3545-3566.

Bilsky, E. (1985). La FORA y el movimiento obrero, 1900-1910, 2 vols. CEAL. Buonuome, J. (2014). La Vanguardia, 1894-1895. Cultura impresa, periodismo y cultura socialista en la Argentina. Tesis de Maestria, Universidad de San Andrés.

Camarero, H. (2015). El Partido Socialista de la Argentina y sus espinosas relaciones con el movimiento obrero: un análisis del surgimiento y disolución del Comité de Propaganda Gremial, 1914-1917. Izquierdas.

Carracedo, O. (1980). El Hogar Obrero, vanguardia de la economía social. Ediciones Cooperativa "El Hogar Obrero".

Ceruso, D. (2017). El Partido Socialista y la cuestión gremial. Debates internos durante la primera mitad de la década infame. Archivos de Historia del Movimiento Obrero y la Izquierda, 10, 119-139.

Graciano, O. (2015). Prácticas académicas y producción de saber de los intelectuales de izquierda en la universidad argentina, 1900-1930. Secuencia, 92, 114-138.

Herrera, C.M. (2016). ¿Adiós al proletariado? El Partido Socialista bajo el peronismo (1945-1955). Imago Mundi.

Horowitz, J. (2004). Los sindicatos, el Estado y el surgimiento de Perón, 1930-1946. Eduntref.

Iñigo Carrera, N. (1996). Documentos para la historia del Partido Socialista. UNCPBA.

Justo, J.B. (1948). Teoría y práctica de la historia. La Vanguardia.

Kriegel, A. (1986). Las internacionales obreras (1864-1943). Orbis.

Lenin, V.I. (1977). El problema de las cooperativas en el Congreso Socialista de Copenhague. En V.I. Lenin, Obras Completas, t. XVI (pp. 273-281). Akal.

Liernur, F. (2014). Precariedad y modernización. La habitación popular en el umbral de la metrópolis. En A. Ballent y F. Liernur. La casa y la multitud. Vivienda, politica y cultura en la Argentina moderna (pp. 57-109). Fondo de Cultura Económica.

Martinez Mazzola, R. (2008). El Partido Socialista y sus interpretaciones del radicalismo argentino (1890-1930). Tesis Doctoral, Universidad de Buenos Aires.

Nari, M. (2004). Politicas de maternidad y maternalismo politico. Buenos Aires, 1890-1940. Biblos.

Oddone, J. (1983). Historia del socialismo argentino [1934]. CEAL.

Palermo, S. (2018). Palabras e imágenes de mujeres en el Partido Socialista: la campaña presidencial de 1916 en Argentina. Estudios Sociales, 55.

Poy, L. (2020). El Partido Socialista argentino, 1896-1912. Una historia social y politica. Ariadna.

Repetto, N. (1976). Cómo nace y se desarrolla una cooperativa. Ediciones Intercoop. 
- (1944). Lecciones de cooperación. Ed. FACC.

Rodríguez Tarditi, J. (1970). Juan B. Justo y Nicolás Repetto en la acción cooperativa. Ediciones Intercoop.

Ronchi, V. (2016). La cooperación integral. Historia de "El Hogar Obrero". Ediciones Fabro.

Scobie, J. (1977). Buenos Aires. Del centro a los barrios. 1870-1910. Ediciones Solar.

Tortti, M.C. (1989). Estrategia del Partido Socialista. Reformismo politico y reformismo sindical. CEAL.

Vandervelde, E. (1913). La coopération neutre et la coopération socialiste. Librairie Félix Alcan.

Walter, R. (1977). The Socialist Party of Argentina, 1890-1930. The University of Texas at Austin.

Wellhofer, E.S. (1975). Political Party Development in Argentina. The Emergence of Socialist Party Parliamentarianism. Journal of Inter-American Studies and World Affairs, 17. 